\title{
EL PUNTO DE VISTA PANORÁMICO EN LA LITERATURA EUROPEA DECIMONÓNICA
}

\author{
Dorde Cuvardic García
}

\begin{abstract}
RESUMEN
Con raíces en la sátira de la antigüedad grecolatina, el punto de vista panorámico es una convención enunciativa típica de los discursos literario, artístico y científico de la Europa de la primera mitad del siglo XIX. Cumple diversas funciones: distanciamiento crítico frente a la realidad observada o, por el contrario, identificación orgullosa con la sociedad. En este artículo se analiza su uso en la literatura costumbrista y realista de diversos países europeos, como es el caso de Víctor Hugo. Se destaca, además, su utilización en la literatura española. Se analizan especialmente cuadros de costumbres de Mariano José de Larra y de Mesonero Romanos, así como el Capítulo 1 de $L a$ Regenta, de Leopoldo Alas "Clarín".

Palabras clave: Punto de vista panorámico, costumbrismo, realismo, comparatismo literario.
\end{abstract}

\begin{abstract}
Rooted in the satire of the Grecolatin Antiguity, the panoramic pint of view is a typical convention of the literary, artistic and scientific discourses of the first half of IXI century Europe. This approach has different functions: it provokes either a critical distance facing the observed reality or a proud identification with society. This article then analyses the use of literature of manners and realism in Spanish literature taking into account authors such as Mariano José de Larra and Mesonero Romanos and the first chapter of Leopoldo Alas "Clarín" La Regenta.
\end{abstract}

Key words: Panoramic point of view, literature of manners, realism, comparative literature.

Dorde Cuvardic García. Profesor de la Escuela de Filología, Lingüística y Literatura, Universidad de Costa Rica. San Pedro, San José, Costa Rica.

Correo electrónico: dcuvardic@yahoo.es 
En el siglo XIX, los libros de tipos sociales y las escenas urbanas del costumbrismo y del realismo tienen una relación literal y metafórica con el punto de vista panorámico. Recuérdese que dos de las modalidades perceptivas y literarias dominantes de evocación de la ciudad decimonónica son el punto de vista panorámico y el repentino encuentro con figuras solitarias (Epstein 1995: 21).

\section{El panorama como enunciación referencial y metafórica}

En términos literales, en algunas escenas urbanas del costumbrismo, el enunciador se posiciona en un lugar elevado de la ciudad y describe sus edificios, sus habitantes. En cambio, metafóricamente hablando, los libros de tipos sociales son panorámicos en su intencionalidad: su pretensión es ofrecer un registro lo más exhaustivo posible de las costumbres y de los tipos sociales 'existentes' en su época. En este sentido metafórico reunió Mesonero Romanos los 23 artículos que publicó en Cartas españolas (1832-1835) bajo el título Panorama Matritense.

La mirada panorámica no sólo es literal, cuando el escritor representa desde un sitio elevado el objeto de su representación, sino también metafórica, cuando afirma describir exhaustivamente los tipos sociales y las costumbres de una nación. Así lo hace el Curioso Parlante en "El Observatorio de la Puerta del Sol", introducción a la Segunda Serie de las Escenas Matritenses, de Mesonero Romanos:

\footnotetext{
Ahora bien: ya estamos en las nubes yo y mi auditorio; ya asestamos los catalejos a esta tierra noble, feraz y en otro tiempo afortunada del globo que se denomina España; ya miramos agitarse a nuestros pies a este pueblo generoso que se llama la capital del pueblo español; las pasiones momentáneas que le agitan no llegan a la altura en que nos hemos colocado; apenas consiguen empañar uno de los infinitos lados del prisma por donde le contemplamos. ¿Qué es la historia filosófica de un pueblo, uno, dos, tres, diez años de existencia borrascosa? ¿Qué es el carácter general de sus habitantes, el de una centena, el de un millar de sus individuos ambiciosos y agitados? El cuadro que tenemos a la vista es más inmenso y magnífico que todo esto: él nos pone de manifiesto el carácter, las inclinaciones, las costumbres generales de toda una sociedad; él nos hace considerar también aisladamente las excepciones, y..., ¡cielos!, ¡qué pequeñas se presentan a nuestra vista estas excepciones que allá abajo mente tanto ruido y pretenden servir de pauta a la regla general! Ellas aparecen y desaparecen en un solo día, y brillan a nuestros ojos como los fuegos fatuos en un dilatado horizonte o como una sombra vacilante en la inmensidad de los mares (Mesonero Romanos 1967: 356-7).
}

El punto de vista panorámico tiene la pretensión de establecer generalizaciones; tiene claras intenciones inductivas. Su propósito es definir las costumbres de los tipos sociales. Las pasiones momentáneas no son objeto de la pintura de Mesonero Romanos, sino "el carácter, las inclinaciones, las costumbres generales" de toda la sociedad madrileña de su tiempo.

\section{El punto de vista panorámico en el costumbrismo europeo}

El punto de vista panorámico en el costumbrismo europeo debe ser interpretado desde la ideología panóptica que la cultura occidental europea venía promoviendo desde el siglo XVIII. El periodismo y la literatura del movimiento costumbrista forman parte de las prácticas discursivas que a partir de aquella época promovieron objetivos de control social orientados a domesticar los rápidos cambios producidos por la modernidad. En el caso de los artículos de costumbres, la perspectiva enunciativa, que habla desde la primera persona del singular, busca obtener un dominio visual de la ciudad oculto a las miradas de los demás: se trata de ver sin ser visto, de registrar (y, por lo tanto, de hacer legible, de controlar) las costumbres de la época. 


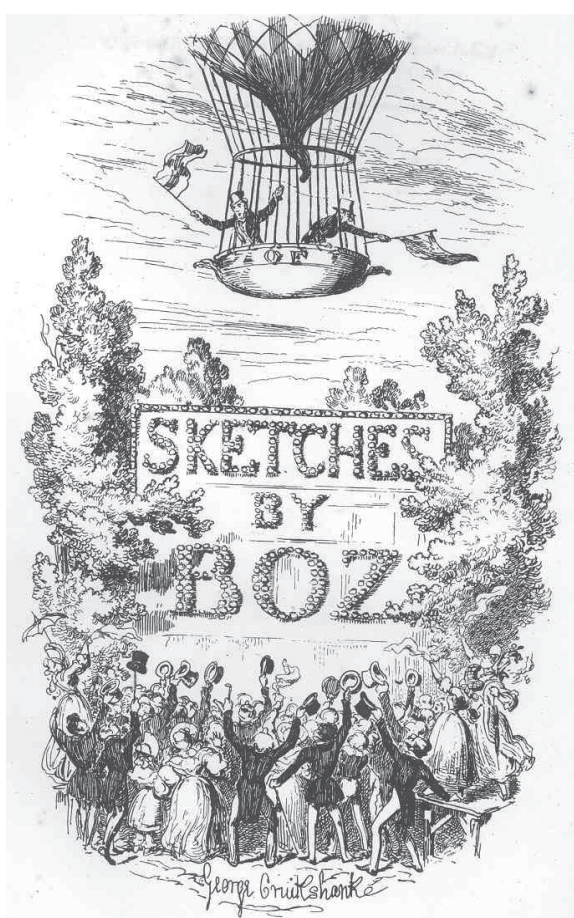

Figura 1. Frontispicio de George Cruikshank para Sketches by Boz. Illustrative of every-day life and every-day people, de Charles Dickens. London: Oxford University Press, 1957.

Esta manifestación delaideologíapanóptica decimonónica se realiza mediante procedimientos satíricos. Y un procedimiento común de la sátira, ya practicado desde la Antigüedad, no es sólo la utilización de personajes distanciados, ajenos a la realidad que critican, sino además, en un buen número de ocasiones, la ubicación de estos personajes en sitios elevados, con el objetivo de observar panorámicamente la sociedad que evalúan. En este sentido, el panorama costumbrista hunde una de sus raíces en el punto de vista promovido por la sátira menipea, como sucede, por ejemplo, en el Caronte, de Luciano de Samosata. Checa (2003: 37) comenta esta contemplación vertical: La visión de los dos espectadores satíricos del Caronte se efectúa desde un lugar elevado, simbólicamente correlativo al dominio intelectual que ambos alcanzan y a su distancia emocional ante las conductas sometidas a examen. Se trata sin duda de un mecanismo narrativo perfectamente familiar para cualquier conocedor de la corriente menipea (en cursiva en el original).

En el ámbito alemán, podemos considerar un caso de mirada panorámica el cuento costumbrista El pariente en la ventana del chaflán, título original traducido como El observatorio, de E.T.A.Hoffmann.

Desde la ventana, el primo del narrador identifica los rostros de los asistentes de un mercado, a los que asignará retratos fisiognómicos:

Sentéme a los pies de mi primo en una banqueta situada en el hueco de la ventana. La vista era en verdad extraña y admirable. Toda la plaza parecía una masa compacta de gente, produciendo la ilusión de que si se tirase en medio de ella una manzana no llegaría al suelo. Los abigarrados colores brillaban al sol en manchas pequeñas. A mí me causaba el efecto de un plantel de tulipanes que oscilase con el viento, y hube de confesar que, a la larga, había de fatigarme mucho aquel constante ir y venir de gente. Me pregunté cuál sería el encanto que mi primo encontraría en aquello, y así se lo dije sin rodeos.

Levantó las manos en alto y entre los dos se entabló la siguiente conversación:

MI PRIMO.- Veo que no tienes ni pizca de talento de escritor. Te falta lo principal para poder seguir las huellas de tu primo, el imposibilitado..., esto es, vista para ver como es debido. Esa plaza no te sugiere más que la idea de una multitud que va y viene. Para mí, en cambio, es la representación de la vida burguesa, y mi espíritu, cual Callot o Chodowiecki, traza croquis tras croquis cuyos contornos suelen tener gran interés. Ven acá a ver si logro iniciarte en el arte de la observación. Mira a la calle; aquí tienes mis gemelos (Hoffmann 1989: 302).

El primo paralítico del cuento El observatorio, hombre burgués ocioso, ejecuta un acto de poder: organiza el mercado que se ofrece a su vista, construye retratos fisiognómicos de la multitud ${ }^{1}$.

En el costumbrismo inglés es muy común el punto de vista panorámico. Así ocurre en el artículo de costumbres inglés "El jardín de té", sketch o cuadro de Cyrus Redding, aparecido en agosto de 1822 en el London Magazine. El narrador observa Londres desde Primrose Hill, 
al norte de Londres, y seguidamente baja a la ciudad para mezclarse con sus conciudadanos, algo que también ejecutará el hipotético provinciano que después de observar Madrid desde la cúpula de la Iglesia de Santa Cruz descienda a las calles de la ciudad, en el artículo Paseo por las calles, de Mesonero Romanos. Considera Deborah Epstein Nord (1995: 21) que en el artículo de Cyrus Redding se representa Londres como una ciudad imperial, activa, desde el orgullo mostrado por el narrador.

Otro ejemplo de visión panorámica en el costumbrismo inglés es Life in London, or The Day and Night Scenes of Jerry Hawthorne, Esq. And his Elegant Friend Corinthian Tom in their Rambles and Sprees through the Metrópolis, de Pierce Egan. Jerry, un caballero rural, y Tom, su primo de la ciudad, visitan la prisión de Newgate, que también describió la escritora franco-peruana Flora Tristán en sus Paseos por Londres en los años 30 del siglo XIX. Desde un punto de vista elevado de la prisión, Tom y Jerry observan con complacencia el racionalismo penal implantado en la prisión al clasificar a los criminales, según sus diferentes crímenes, en el más estricto régimen disciplinario (Epstein 1995: 35). Por otra parte, la intencionalidad socialmente panorámica de los Sketches by Boz, de Charles Dickens, se puede ver en la alegoría del globo aerostático que preside el frontispicio del libro.

\section{El punto de vista panorámico en el costumbrismo español y latinoamericano}

En el marco de la pretensión panorámica del costumbrismo decimonónico se utiliza al barroco diablo cojuelo como metáfora. Asmodeo, el diablo cojuelo de la obra de Luis Vélez de Guevara, es liberado por el hidalgo Don Cleofás. Como recompensa, le ofrece un recorrido por los techos de Madrid: levanta los tejados para observar la vida que se desarrolla entre las paredes de las viviendas madrileñas. Asmodeo le enseña a Don Cleofás lo que sucede tras los techos de Madrid².

\footnotetext{
-Don Cleofás, desde esta picota de las nubes (es decir, la torre de San Salvador, mayor atalaya de San Salvador), que es el lugar más eminente de Madrid, malaño para Menipo en los diálogos de Luciano, te he de enseñar todo lo más notable que a estas horas pasa en esta Babilonia española, que en la confusión fue esotra con ella segunda deste nombre.

Y levantando a los techos de los edificios, por arte diabólica, lo hojaldrado, se descubrió la carne del pastelón de Madrid como entonces estaba, patentemente, que por el mucho calor estivo estaba con menos celosías, y tanta variedad de sabandijas racionales en esta arca del mundo, que la del diluvio, comparada con ella, fue de capas y gorras.
}

Esta escena de El diablo cojuelo será adaptada por José Mariano de Larra en el artículo de costumbres El mundo todo es máscaras. Todo el año es Carnaval, publicado en El pobrecito hablador el 14 de marzo de 1833. La intención enunciativa es ofrecer una sátira contra la hipocresía social. Cansado de escuchar y de observar un baile de máscaras, $E l$ pobrecito hablador decide dormitar en un rincón del salón. Asmodeo, el protagonista de El diablo cojuelo, se le aparece y le dice:

-Te conozco -me dijo-, no temas; vienes a observar el carnaval en un baile de máscaras. ¡Necio!, ven conmigo; do quiera hallarás máscaras, do quiera carnaval, sin esperar al segundo mes del año (Larra 1992: 214).

Aunque el carnaval supone el reconocimiento y la aceptación, entre los ciudadanos, de la interacción social cotidiana como teatro, como despliegue de diversas máscaras -o de 
diversas fachadas-, El pobrecito hablador comprueba que también en los bailes de máscaras el ser humano engaña a sus semejantes: como un espacio más del teatro social, es el lugar, por ejemplo, donde se prepara el adulterio. El Diablo Cojuelo quiere demostrarle, en todo caso, que el ejercicio de la hipocresía, de las máscaras, caracteriza al ser humano en cualquier espacio social. Con este propósito, Asmodeo conduce al Bachiller al cielo de Madrid:

\footnotetext{
Arrebatóme entonces insensible y rápidamente, no sé si sobre algún dragón alado, o vara mágica, o cualquier otro bagaje de esta especie. Ello fue que alzarme del sitio que ocupaba y encontrarnos suspendidos en la atmósfera sobre Madrid, como el águila que se columpia en el aire buscando con vista penetrante su temerosa presa, fue obra de un instante. Entonces vi al través de los tejados como pudiera al través del vidrio de un excelente anteojo de larga vista (Larra 1992: 214).
}

Asmodeo invita a Fígaro a observar diversos engaños que tienen lugar durante el Carnaval: infidelidades matrimoniales, por ejemplo. Mientras que en Cyrus Redding (observación del Londres imperial), en Pierce Egan (observación de la ideología disciplinaria), el punto de vista panorámico incentiva el orgullo de la instancia enunciativa frente al progreso de la sociedad observada, la perspectiva asumida en el artículo de Larra es satírica, desfamiliarizadora.

Conocido es el uso del perspectivismo en el costumbrismo. Se describe en muchos artículos de costumbres la perspectiva del provinciano recién llegado a la ciudad. En el ya mencionado Paseo por las calles, de Mesonero Romanos, el narrador considera que una de las primeras acciones que realizaría el hipotético provinciano recién llegado a la capital sería observar la ciudad desde las alturas, antes de que iniciara su paseo por las calles. La primera visión urbana del visitante tendría carácter panorámico. A diferencia de la actitud del personaje del artículo de Cyrus Redding, orgulloso del Londres imperial que observa, el provinciano del artículo de Mesonero Romanos se desilusionará ante la sordidez de los tejados de la corte.

\footnotetext{
Si deseando modificar estas primeras impresiones, y conocer a un golpe de vista el conjunto del pueblo que los recibe, solicitasen subir a una altura céntrica y de la elevación correspondiente para medir y conocer a vista de pájaro todo el plano de la capital, sería aún más difícil el indicársela, careciendo, como carecemos, de un gran templo central, que suele ser en otros pueblos el sitio adonde los forasteros acuden para satisfacer este deseo. La torre de la parroquia de Santa Cruz es la única que puede suplir en Madrid aquella falta, aunque ni su elevación ni su situación son suficientes para abrazar distintamente todo el plano, y conocer a un golpe de vista las varias fisonomías de los cuarteles de esta villa. Sin embargo, colocados en aquella altura puede observarse el corte de la población, uno de los más cómodos y ventajosos que conocemos, pues que partiendo sus calles principales de un centro común, que es la Puerta del Sol, se prolongan en forma de estrella hasta los últimos confines de la villa. (...) Por lo demás, en cuanto a la belleza del aspecto general, menguada idea podrá formar desde aquel punto, no divisando desde él sino la desigualdad, tristeza y mezquina forma de los tejados de nuestras casas. (Mesonero Romanos 1993: 218-20).
}

Posteriormente, una vez situado al nivel del suelo, el provinciano ejecuta la visión del transeúnte.

Durante varios siglos, el campanario de la iglesia de Santa Cruz fue el punto más alto de Madrid. Así lo señalan Vélez de Guevara, Mesonero Romanos y, en cita que presentamos a continuación, Benito Pérez Galdós, quien en un artículo periodístico titulado "Desde la veleta" construye la vista de pájaro o vista panorámica como punto de vista descriptivo. Este artículo apareció en La Nación el 7 de enero de 1866. Pertenece a su etapa costumbrista (antes de la publicación de sus novelas):

Qué magnífico sería abarcar en un solo momento toda la perspectiva de las calles de Madrid, ver el que entra, el que sale, el que ronda, el que aguarda, el que acecha, ver el camino de este, el encuentro, 
la sorpresa del otro; seguir al simón que es bruscamente alquilado para dar cabida a una amable pareja; verle divagar como quien no va a ninguna parte; verle parar depositando sus tórtolos allí donde un ojo celoso no se oculte entre el gentío; ver el carruaje del ministro, pedestal ambulante de dos escarapelas rojas, dirigirse a la oficina o a Palacio, procurando llegar antes que el coche del nuncio; mirar hacia la Castellana y ver la vanidad arrastrada por elegantes cuadrúpedos, midiendo el reducido paseo, como si el premio de una regata se prometiera al que da más vueltas; sorprender las maquinaciones amorosas que en aquel laberinto de ruedas se fraguan durante el momentáneo encuentro de vehículos; ver al marido y a la mujer arrastrados en dirección contraria, rodando el uno hacia el naciente y la otra hacia poniente, permitiéndose, si se encuentran, el cambio de un frío saludo; ver la gente pedestre en el paseo de la izquierda contemplando con envidia la suntuosidad del centro; seguir el paso incierto del tahúr que se encamina al garito; ver descender la noche sobre la villa y proteger en su casta oscuridad la pesca nocturna que hacen en las calles más céntricas las estucadas ninfas de la calle de Gitanos; oír la serenata que suena junto al balcón y contemplar la rendija de luz que indica la afición musical de la beldad que vela en aquella alcoba; esperar el día y ver la escuálida figura del jugador que, tiritando y soñoliento, entra en el café a confortarse con un trasnochado chocolate; ver los mercados abriendo al público sus pestíferos aramarios; ver al sacristán moviendo el pesado cerrojo de la puerta santa y contar las primeras mojigatas que suben las sucias escaleras del templo; ver de quién es el primer cuarto que recoge el ciego en su mano petrificada; ver salir de una puerta un ataúd gallegamente conducido, y saber dónde ha muerto un hombre; ver salir a un comadrón y saber dónde ha nacido un hombre; ver... pero adónde vamos a parar.

¡Cuántas cosas veríamos de una vez si el natural aplomo y la gravedad de nuestra humanidad nos permitieran ensartarnos a nuestra veleta en el campanario de Santa Cruz, que tiene fama de ser el más elevado de esta campanuda villa del oso! ¡Cuántas cómicas o lamentables escenas se desarrollarían bajo nosotros! ¿Qué magnífico punto de vista es una veleta para el que toma la perspectiva de la capital de España! (Benito Pérez Galdós, "Desde la veleta", Crónica de Madrid, enero 7 de 1866, recogido en O.C., t.6, 1942, pp. 1617-1618, y reproducido en Los artículos de Galdós en La Nación, Madrid, Ínsula, 1972).

Como ya mencionamos antes, no toda descripción panorámica costumbrista tiene por función celebrar el esplendor de la Nación, el carácter emprendedor y vitalista de la sociedad: la perspectiva enunciativa, en estos casos, reflexionará sobre la vanidad de los proyectos y las actividades humanas. La visión a vista de pájaro se constituye en reflexión de la soberbia humana, de la fugacidad de las empresas humanas. En El camposanto, de 1832, el Curioso Parlante, sobre el cubierto de una capilla de un cementerio madrileño, reflexiona:

Yo tendí la vista por los seis uniformes patios, y después sobre otro recinto adjunto, en medio del cual vi un elegante mausoleo que la piedad filial ha elevado al defensor de Madrid no lejos del sitio en que inmortalizó su valor. Después, salvando las murallas, fijé los ojos en la populosa corte, cuyo lejano rumor y agitación llegaba hasta mí...iqué de pasiones encontradas, qué de intrigas, qué movimiento! y todo ¿para qué?... para venir a hundirse en este sitio... (Mesonero Romanos 1993: 202).

El costumbrismo hispanoamericano también utilizó esta convención. El escritor argentino Juan García Gutiérrez utiliza en su artículo El hombre hormiga, publicado originalmente en La Moda, de Buenos Aires, el punto de vista panorámico. Sitúa al narrador en un lugar elevado que le permitirá describir, mediante el procedimiento retórico de la enumeración caótica, las escenas y los tipos sociales que bullen a ras de suelo, en la calle:

Colóquese un curioso en alguna altura de las calles más concurridas: en donde haya almacenes, tiendas de ropa hecha, alguna iglesia inmediata, el despacho de algún cambista, y vinos y comestibles en cada puerta; desde allí sentirá el hervir vividor de las gentes que van y vienen: niños, mujeres, viejos y mozos; unos corren, otros vuelan, pocos andan despacio, se miran, se saludan, conversan entre sí, todo es movimiento y bulla: "Cuidado con la rueda, apártate del caballo, mira esa reja", dicen las madres a sus chicos distraídos con la confiterías. "Dispense Vd. Que le he pisado", dice un corredor que va como D. Cleofás en alas del cojuelo. “Zapallos! ... ¡Pepinos!...jPara las benditas ánimas!...” "A cómo la docena?” "B. A V. La mano”, etc. ¡Tal es la vocinglería que se escucha! Voces escapadas de las mil bocas de aquel monstruo que se agita y revuelve en las veredas. Tenga paciencia el curioso: colocado a dicha alguna, ¿no le parecen los ciudadanos yentes y vinientes hormigas que van y vienen al granero? Ni más ni menos: unos y otras negras a la distancia: unos y otras cargados en la cabeza, con comestibles o con buenos yo malos pensamientos; 
unos y otras devastan, unos y otras no se contentan con los necesario: ellas guardan para el invierno, ellos amontonan para la vejez, que es el invierno de la vida (en cursiva en el original) (Gutiérrez 2000: 58).

Destaquemos la mención de Don Cleofás y de El diablo cojuelo, los personajes de la novela de Luis Vélez de Guevara. Juan María Gutiérrez utiliza el sintagma hervir vividor donde los demás costumbristas suelen utilizar el de cuadro o espectáculo animado. Desde el punto de vista panorámico describe la actividad urbana callejera. La distancia física difumina los rasgos humanos de la masa, imbuida, por el contrario, de atributos pertenecientes al discurso zoológico y botánico.

La mirada panorámica también cumple la función, perteneciente a la ideología de la objetividad, de ofrecer una imagen no distorsionada, o sesgada, de la sociedad. Con la pretensión de levantar los techos de la ciudad de Madrid, Mesonero Romanos pretende responder a los escritores extranjeros que describen erróneamente el carácter español, como sucede en El dominó (febrero de 1833), artículo en el que El Curioso Parlante pretende refutar los estereotipos nacionales propuestos más allá de las fronteras:

\begin{abstract}
¡Oh, quién fuera ahora Vélez de Guevara o Lesage, para tener a mis órdenes un diablillo Asmodeo, aunque fuese cojo, que me ayudase a levantar los techos de las casas de Madrid, para presentar su interior a los que aún se empeñan en caracterizarnos a su antojo! Verían si es, como ellos dicen, sombrío y taciturno un pueblo que a la hora en que escribo olvida alegremente sus cuidados, moviéndose a compás; dijéranme si es miserable este mismo pueblo, que tan crecidas sumas gasta en magníficas funciones, ostentando en todas ellas la riqueza y el buen gusto; verían, en fin, si son tan celosos nuestros maridos, tan altivas nuestras mujeres, tan intratables nuestros padres, tan rendidos nuestros amantes, tan espesas nuestras celosías, tan temibles nuestros pañales (Mesonero Romanos 1967: 230).
\end{abstract}

\title{
4. El punto de vista panorámico en la novela realista
}

Ya afirmamos previamente que el punto de vista panorámico es un recurso enunciativo decimonónico ejecutado en diversas artes. En este apartado realizaremos un análisis del punto de vista panorámico en otra práctica significante: la novela. Como señala Parkhurst Ferguson (1989: 60), "(1)a vista distanciada fue un tema central de las novelas urbanas del siglo XIX”. Es muy útil la enumeración que Parkhurst Ferguson (1989: 61, nota 17) hace de obras que trabajan con el bird's eye view en la narrativa francesa e inglesa decimonónica. En su recensión, ha identificado el punto de vista panorámico en cuatro novelas de Émile Zola: La Débable (la vista final del incendio de París); L'assommoir (el ascenso a los invitados de una boda a la cúspide de la columna de la Plaza Vendôme); Une page d'amour (cuando, apostada en la ventana en la noche, Jeanne espera la llegada de su madre); y Les trois Villes -Las tres ciudades-París- (en la vista final). En Charles Dickens, Ferguson también menciona el caso del capítulo "Town and Todgwers's", de la novela Martín Chuzzlewit (1844), una de las menos conocidas del autor, y la visión histórica con la que termina Historia de dos ciudades (1859).

El romántico Victor Hugo trabajó el punto de vista panorámico en el capítulo "París a vista de pájaro" de la novela Notre-Dame de Paris (1831), y en "París a vista de búho", de Los miserables (1862), treinta y un años después. En el primer caso, la descripción es más detenida. La comentaremos detalladamente más adelante. En el segundo caso, en "París a vista de búho", de Los miserables, el narrador incorpora al lector como narratario observador, a quien podrá orientar en la descripción que ofrece. Es decir, le 'llevará de la mano' desde las alturas de París. Las referencias al narratario son cuatro: "Un ser que hubiera podido cernerse sobre París en aquel momento con las alas del murciélago o del mochuelo, habría descubierto 
un lúgubre espectáculo" (Hugo 1970: 707); “Todo el antiguo barrio del Mercado [...], se le habría presentado como un enorme agujero sombrío en el centro de París" (Hugo 1970: 708); "El que hubiera mirado desde lo alto en este conjunto de sombras..." (Hugo 1970: 708); “... el observador habría podido distinguir...” (Hugo 1970: 708). ¿Por qué Víctor Hugo titula esta sección de la novela 'París a vista de búho'? Este animal, como el murciélago, tiene una vista atrofiada. Sólo llega a reconocer manchas de contornos difuminados. El narrador utiliza la visión del búho y del murciélago como metáfora de la percepción fantasmal que tiene del París revolucionario nocturno: configura la representación de las calles a partir de sombras, de resplandores, de perfiles...

Balzac también trabajó el punto de vista panorámico. Dos ejemplos son las miradas panorámicas de Eugène de Rastignac en Papá Goriot y de Jules Desmarets en Ferragus. En el primer caso, la visión panorámica se constituye en oportunidad para verbalizar un desafío largamente planificado dirigido a la sociedad burguesa. El 'héroe problemático' Rastignac aprovechará el punto de vista panorámico que observa desde el cementerio Pére Lachaise para lanzar un reto a París como parte de su proyecto de escalada social:

\footnotetext{
Al quedar solo, Rastignac dio algunos pasos hacia la parte alta del cementerio, y desde allí vio Paris, extendido tortuosamente a las dos orillas del Sena, donde comenzaban a brillar las luces. Sus ojos se detuvieron casi con avidez entre la columna de la plaza Vendôme y la cúpula de los Inválidos, allí donde vivía aquel mundo resplandeciente en el que había querido introducirse. Lanzó sobre aquella bulliciosa colmena una mirada que parecía gustar de antemano la miel del triunfo, y dijo estas grandiosas palabras:

- ¡A Ahora nos veremos!

Y como primer acto del reto que había lanzado a la sociedad, Rastignac se fue a comer a casa de la señora de Nucingen (Balzac 2001: 244).
}

Sin embargo, no siempre utiliza el narrador la vista panorámica para identificarse con el progreso de la sociedad cuya metrópoli observa o para imaginar que ejerce o ejercerá poder sobre ella algún día. A veces la utiliza como despedida final. Un ejemplo de esta la encontramos en Álvaro Mendiola, de Señas de identidad, de Juan Goytisolo, quien escoge el punto de vista panorámico para proclamar, mientras observa desde Monjuic la ciudad de Barcelona, su programa narrativo de renuncia definitiva a la sociedad española.

Ahora nos situamos en los dos casos que centrarán el análisis del resto de este apartado. La interpretación de la ciudad desde el campanario de una iglesia aparece tanto en Nuestra Señora de París, de Víctor Hugo, como en La Regenta, de Leopoldo Alas Clarín. Dado que desde finales del siglo XVIII se venía desarrollando una cultura panóptica, con uno más de sus indicadores en la efímera moda de la ascensión a los campanarios (Aumont 1997: 39), no debe extrañar que los escritores decimonónicos, imbuidos de la cultura de su época, utilicen este punto de vista panorámico desde el campanario de las iglesias como excusa para ejecutar la radiografía física y socioeconómica de las ciudades o para ofrecer una pequeña lección de historia urbana a sus lectores.

El Capítulo II del Libro tercero de Nuestra Señora de París, de Víctor Hugo, tiene por título "París a vista de pájaro". La narración se ubica a finales del siglo XV. El narrador considera que la principal belleza de esta capital, en la época mencionada, es aquella "que se descubría desde lo alto de sus torres" (Hugo 2001: 121). Utilizando el recurso enunciativo de situar al lector, en su función textual de narratario, en lo alto de la catedral de Nuestra Señora, afirma que, desde este sitio, "era un bello cuadro el que se desarrollaba a la vez por todas partes ante vuestros ojos; un espectáculo sui generis, del cual pueden formarse idea aquellos de nuestros 
lectores que hayan tenido la suerte de ver una ciudad gótica entera, completa, homogénea, como algunas que quedan" (en cursiva en el original) (Hugo 2001: 121). A continuación, se utiliza el procedimiento descriptivo de la hipotiposis, cuya función consiste en detallar vívidamente, como si estuviera presente ante el lector, lo que ha desaparecido en el tiempo: el París del siglo $\mathrm{XV}$. En el caso que nos ocupa, situar al lector en el pasado como narratario observador se constituye en una táctica que facilita el despliegue de este procedimiento.

Después de describir 'a grandes rasgos' la historia de los tres grandes sectores de París (la Ciudad, la Universidad, la Villa) desde los orígenes de la ciudad hasta el siglo XV, el narrador reinicia su uso de la convención de la vista de pájaro mediante la hipotiposis. Después de un primer momento, en el que sólo se percibe el caos urbano, el observador encuentra un principio organizador:

A vista de pájaro, estos tres pueblos, la Ciudad, la Universidad, la Villa, presentaban cada uno a la mirada
una malla inextricable de calles caprichosamente embarulladas. Sin embargo, al primer golpe de vista se
reconocía que estos tres fragmentos de ciudad formaban un solo cuerpo (Hugo 2001: 125).

Aquel observador que despliegue una mirada panorámica, a vista de pájaro, formulará un sistema que logrará organizar la ciudad. El narrador se ocupa entonces de describir los nombres de las calles y su orientación. Como ocurre siempre que la novela romántica o realista se refiere a las vías de comunicación urbanas, se emplean metáforas procedentes de la ciudad-organismo: "Las otras venas de la triple ciudad venían a nutrirse o a desembocar en aquéllas" (Hugo 2001: 125).

Después de esta descripción, el narrador decide reiniciar el uso de la convención de la vista de pájaro y del procedimiento de la hipotiposis. El narrador propone entonces una pregunta retórica: "Ahora bien: ¿bajo qué aspecto se presentaba este conjunto, visto desde lo alto de las torres de Nuestra Señora, en 1482? Esto es lo que vamos a intentar decir" (Hugo 2001: 126). Esta pretensión tratará de ser contestada mediante el recurso de un narratario que suba a las torres de la catedral parisina. El narrador representará el deslumbramiento del narratario observador con la utilización del procedimiento de la enumeración caótica, típico en la descripción urbana. La táctica retórica de incorporar en las descripciones sublimes de la naturaleza y de la ciudad un narratario que represente al lector tiene por propósito provocar la empatía de este último hacia el entusiasmo que el personaje observador experimenta:

\footnotetext{
Para el espectador que llegaba sin aliento allá arriba, era al pronto un deslumbramiento de tejados, de chimeneas, de calles, de puentes, de plazas, de agujas, de campanarios. Todo atraía vuestros ojos a la vez: la pared tallada, el techado agudo, la torrecilla suspendida en los ángulos de los muros, la pirámide de piedra del siglo XI, el obelisco de pizarra del XV, la torre redonda y desnuda del castillejo, la torre cuadrada y bordada de la iglesia, la grande, la pequeña, la maciza, la aérea. La mirada se perdía mucho tiempo en toda la profundidad de este laberinto, donde no había nada que no tuviese su originalidad, su razón, su genio, su belleza; nada que no viniese del arte, desde la menor casa de delantero pintado y esculpido, de armadura exterior, de puerta abocinada, de pisos desnivelados, hasta el real Louvre, que tenía entonces una columnata de torres. Pero he aquí las principales masas que se distinguían cuando la vista comenzaba a habituarse [a] aquel tumulto de edificios (Hugo 2001: 126).
}

El narrador señala que el sector central, la Ciudad o Cité, es comprendida por el observador aéreo como un barco. La vista panorámica metaforiza los objetos percibidos. Otro ejemplo es la cabecera emplomada de la Santa Capilla, parecida "a la grupa de un elefante cargado con su torre" (Hugo 2001: 127).

El resto del capítulo se dedica a describir, con mirada más cercana o más distanciada, los edificios y las situaciones humanas que el lector, como observador del París del siglo XV, puede apreciar desde las alturas. Termina con una descripción, desde la retórica de lo sublime, 
del concierto de campanas que, procedentes de todas las iglesias, podría llegar a escuchar aquel lector que, trasladado al siglo XV, subiera un día festivo a un lugar elevado de la capital.

Por otra parte, la descripción panorámica de Vetusta que aparece en el primer capítulo de La Regenta tiene a Nuestra Señora de París como modelo directo. Se estructura en dos partes: la primera caracteriza, como táctica metonímica, la personalidad del Provisor (se trata de introducir al lector a la etopeya o perfil psicológico de don Fermín a partir de una de sus actividades más singulares, observar la ciudad con un catalejo desde la torre de la catedral, expresión, por lo demás, de sus intenciones como eclesiástico: vigilar las almas de los vetustenses); la segunda se constituye en una radiografía socioeconómica de Vetusta. En La Regenta, el narrador interpreta la afición de don Fermín de Pas por las atalayas naturales y urbanas como una indicación (como un index) de su ambición.

Después de describir la afición del Magistral, el narrador, tomando como excusa la observación de Vetusta por don Fermín desde el catalejo, se dedica a describir sociológica, histórica y arquitectónicamente los barrios de la ciudad de Vetusta, principalmente la Encimada y la Colonia:

\begin{abstract}
Uno de los recreos solitarios de don Fermín de Pas consistía en subir a las alturas. Era montañés, y por instinto buscaba las cumbres de los montes y los campanarios de las iglesias. En todos los países que había visitado había subido a la montaña más alta, y si no las había, a la más soberbia torre. No se deba por enterado de cosa que no viese a vista de pájaro, abarcándola por completo y desde arriba. (...) Cuánto más subía más ansiaba subir; en vez de fatiga sentía fiebre que les daba vigor de acero a las piernas y aliento de fragua a los pulmones. Llegar a lo más alto era un triunfo voluptuoso para De Pas. Ver muchas leguas de tierra, columbrar el mar lejano, contemplar a sus pies los pueblos como si fueran juguetes, imaginarse a los hombres como infusorios, ver pasar un águila, o un milano, según los parajes, debajo de sus ojos, enseñándole el dorso dorado por el sol, mirar las nubes desde arriba, eran intensos placeres de su espíritu altanero que De Pas se procuraba siempre que podía. Entonces sí que en sus mejillas había fuego y en sus ojos dardos. En Vetusta no podía saciar esta pasión; tenía que contentarse con subir algunas veces a la torre de la catedral. (...) (El magistral) paseaba lentamente sus miradas por la ciudad escudriñando sus rincones, levantando con la imaginación los techos, aplicando su espíritu a aquella inspección minuciosa, como el naturalista estudia con poderoso microscopio las pequeñeces de los cuerpos. No miraba a los campos, no contemplaba la lontananza de montes y nubes; sus miradas no salían de la ciudad.

Vetusta era su pasión y su presa. Mientras los demás le tenían por sabio teólogo, filósofo y jurisconsulto, él estimaba sobre todas su ciencia de Vetusta. La conocía palmo a palmo, por dentro y por fuera, por el alma y por el cuerpo, había escudriñado los rincones de las conciencias y los rincones de las casas. Lo que sentía en presencia de la heroica ciudad era gula; hacía su anatomía, no como el filósofo que sólo quiere estudiar, sino como el gastrónomo que busca bocados apetitosos; no aplicaba el escalpelo, sino el trinchante ("Clarín" 2000: 52-4).

Don Fermín de Pas contemplaba la ciudad. Era una presa que le disputaban, pero que acabaría de devorar él solo. ¡Qué! ¿También aquel mezquino imperio habían de arrancarle? No, era suyo. Lo había ganado en buena lid. ¿Para qué eran necios? También al Magistral se le subía la altura a la cabeza; también él veía a los vetustenses como escarabajos; sus viviendas viejas y negruzcas, aplastadas, las crían los vanidosos ciudadanos palacios y eran madrigueras, cuevas, montones de tierra, labor de topo... ¿Qué había hecho los dueños de aquellos palacios viejos y arruinados de la Encimada que él tenía allí a sus pies? ¿Qué había hecho él? Conquistar (“Clarín” 2000).
\end{abstract}

Esta descripción socioeconómica panorámica de Vetusta (panorámica en términos literales, al partir de un puesto de observación elevado y distanciado, y en términos metafóricos, por su carácter exhaustivo) no es solamente científica: también permite acercarnos a las ambiciones sociales del Magistral. Se describe primero el casco antiguo, con el barrio de la Encimada, repleto de calles estrechas y húmedas, de iglesias, de caserones pertenecientes a la nobleza descapitalizada, de tugurios de pobres que no pueden pagar una vivienda en las afueras de la ciudad... En segundo lugar se describe el barrio de la Colonia, donde viven los indianos y la burguesía local recientemente enriquecida. 
Tanto Nuestra Señora de París como La Regenta fragmentan París y Vetusta, respectivamente, en 'estratos geológicos'. Este tipo de representación es común en el costumbrismo, que tantos préstamos recibió de la pseudociencias de la época. Como señala Susan Stewart (1984: 78), “(s)i intentamos describir la ciudad desde una posición distanciada y trascendente, y de este modo a miniaturizarla, la tendencia es a naturalizar el paisaje urbano". El posterior realismo asumió este uso literario del discurso geológico.

Finalmente, La Regenta no sólo describe y narra el intento de don Fermín por dominar las almas de los habitantes de Vetusta, sino también el dominio panóptico que ejerce la Iglesia sobre la sociabilidad pública y la sexualidad privada de la ciudad. ¿Cómo se lleva a cabo este dominio? Al incitar a sus habitantes a ejercer un constante espionaje y control sobre cada uno de los actos de sus vecinos. En este sentido, la torre de la catedral, que espía a Ana Ozores e incluso a don Fermín (en giro irónico), es metáfora del ojo público, escrutador e inquisitivo, que el ejercicio hipócrita de la religión ha promovido en los ciudadanos:

\begin{abstract}
La noche corría a todo correr. La torre de la catedral, que espiaba a los interlocutores de la glorieta desde lejos, entre la niebla que empezaba a subir por aquel lado, dejó oír tres campanadas como un aviso. Le parecía que ya habían hablado bastante. Pero ellos no oyeron la señal de la torre que vigilaba (“Clarín” 2000: 480).
\end{abstract}

\title{
5. Parodia de la convención decimonónica de la 'vista de pájaro': Adán Buenosayres
}

En Adán Buenosayres se funden dos convenciones del discurso descriptivo sobre la urbe: la visión panorámica de la ciudad y la llegada a esta desde el mar, remontando la desembocadura del río. La descripción de la ciudad mediante la llegada del narrador en barco se encuentra en el primer párrafo del capítulo "Las grandes ciudades", en La situación de la clase obrera en Inglaterra, de Federico Engels. En este texto, el narrador considera que el espectáculo ofrecido al recién llegado no es sino una máscara: detrás de los fastos que aparecen en las márgenes del Támesis, primera impresión recibida por el recién llegado, se encuentran los barrios de miseria que, en última instancia, vienen a sostener económicamente la opulencia visible.

Por lo que respecta a la visión a vista de pájaro o panorámica, el narrador de Adán Buenosayres conoce la función festiva que desempeñó esta convención en la literatura costumbrista y, desde su perspectiva paródica, se burla de ella como procedimiento descriptivo en el inicio del segundo párrafo de la novela:

\footnotetext{
Templada y riente (como lo son las del otoño en la muy graciosa ciudad de Buenos Aires) resplandecía la mañana de aquel veintiocho de abril: las diez acababan de sonar en los relojes, y a esa hora, despierta y gesticulante bajo el sol mañanero, la Gran Capital del Sur era una mazorca de hombres que se disputaban a gritos la posesión del día y de la tierra. Lector agreste, si te adornara la virtud del pájaro y si desde tus alturas hubieses tendido una mirada gorrionesca sobre la ciudad, bien sé yo que tu pecho se habría dilatado según la mecánica del orgullo ante la visión que a tus ojos de porteño leal se hubiera ofrecido en aquel instante. Buques negros y sonoros, anclando en el puerto de Santa María de los Buenos Aires, arrojaban a sus muelles la cosecha industrial de los dos hemisferios, el color y el sonido de las cuatro razas, el yodo y la sal de los siete mares; al mismo tiempo, atorados con la fauna, la flora y la gea de nuestro territorio, buques altos y solemnes partían hacia las ocho direcciones del agua entre un áspero adiós de sirenas navales. Si desde allí hubieses remontado el curso del Riachuelo hasta la planta de los frigoríficos, te habría sido posible admirar los bretes desbordantes de novillos y vaquillonas que se apretaban y mugían al sol esperando el mazazo antes las dos astas y el hábil cuchillo de los matarifes listos ya para ofrecer una hecatombe a la voracidad del mundo. Trenes orquéstales entraban en la ciudad, o salían rumbo a las florestas del norte, a los viñedos del oeste, a las geórgicas del centro y a las pastorales
} 
del sur. Desde Avellaneda la fabril hasta Belgrano ceñíase a la metrópoli un cinturón de chimeneas humeantes que garabateaban en el cielo varonil del suburbio corajudas humeantes de Rivadavia o de Sarmiento. Rumores de pesas y medidas, tintineos de cajas registradoras, voces y ademanes encontrados como armas, talones fugitivos parecían batir el pulso de la ciudad tonante; aquí los banqueros de la calle Reconquista manejaban la rueda loca de la Fortuna; más allá ingenieros graves como la Geometría meditaban los nuevos puentes y caminos del mundo. Buenos Aires en marcha reía: Industria y Comercio la llevaban de la mano (...)

Pero refrena tu lirismo, encabritado lector, y descolgándote de la región excelsa en que te puso mi estilográfica desciende conmigo al barrio de Villa Crespo, frente al número 303 de la calle Monte Egmont: allá, barriendo a grandes trazos la vereda, Irma gritaba los versos iniciales de «El Pañuelito»" (Marechal 1997: 7-8).

Se parodia el uso ideológicamente triunfalista que el costumbrismo y el realismo burgueses han conferido a la convención de la vista de pájaro ${ }^{3}$.Se realiza una estilización paródica de las descripciones urbanas, glorificadoras del progreso industrial, amparadas en la vista de pájaro. En Adán Buenosayres se parodia explícitamente la vista de pájaro, la perspectiva panorámica, como un punto de vista afectivamente distanciado, nada comprometido con las penalidades cotidianas de los habitantes de las grandes ciudades. Durante el costumbrismo permitió describir panorámicamente, con el recurso estilístico de la enumeración caótica, la ciudad bazar, con su efervescencia comercial, sin preocuparse por representar los problemas sociales que conllevó la industrialización de las sociedades occidentales.

\section{Conclusión}

El arte y la literatura occidentales han concedido preferencia a la representación visual. Un ejemplo aparece con la llamada vista panorámica. La mirada olímpica, la mirada desde el campanario, la mirada desde la buhardilla del artista, la mirada desde la cumbre o las laderas del monte (en busca de lo sublime prerromántico), la mirada desde el balcón o la ventana, expresan las diferentes actitudes que los enunciadores, en el siglo XIX, han asumido ante la naturaleza o la sociedad: melancólica, entusiasmada, dominante. En el costumbrismo y en el realismo, particularmente, el punto de vista panorámico expresa tanto los elogios como las críticas que los intelectuales y los artistas otorgaron a sociedades europeas en constante cambio social.

\section{Notas}

1. Walter Benjamin considera la mirada panorámica desde la ventana, tomando como ejemplo este cuento, interpretativamente menos profunda que la mirada del flâneur que merodea por las calles y otros espacios públicos de la ciudad. Aunque ambos observan la multitud, el flaneur de El hombre de la multitud, de Edgar Allan Poe sale mejor parado que el burgués voyeurista de El observatorio, de E.T.A. Hoffmann, ya que en el primer caso el narrador queda atraído por una multitud que no se deja interpretar, mientras que en el segundo, el primo del narrador asigna sin obstáculos sus caracterizaciones fisiognómicas. Benjamin afirma:

Pero qué apocada es la mirada sobre la multitud de quién está instalado en su vida casera. Y qué penetrante es la del hombre absorto en ella a través de las lunas de los cafés. En la diferencia de los puestos de observación estriba la diferencia entre Berlín y Londres. De un lado el rentista; se sienta en el mirador como en una platea; y cuando quiere darse una vuelta por el mercado, tiene en la mano unos gemelos de ópera. De otro lado el consumidor, el innominado, que entra en el café y en seguida lo abandona atraído por el imán de la masa que incansablemente le vapulea. De un lado un gran surtido de pequeñas estampas 
de género que forman todas ellas un álbum de láminas coloristas; de otro lado un bosquejo que hubiese podido inspirar a un gran grabador; una multitud inabarcable en la que nadie está del todo claro para el otro y nadie es para otro enteramente impenetrable (1998: 64).

2. Enrique Cepeda y Enrique Rull, en su prólogo a una edición de 1968 a El diablo cojuelo (citado en Assaf 1984: 407), señalan correlaciones de este texto con uno previo: Los Antojos de mejor vista, de Rodrigo Fernández de Ribera (hacia 1620), en el que un gentilhombre regresa a su ciudad natal, Sevilla; subido a su torre más alta, observa y comenta lo que ve.

3. Hemos encontrado otro ejemplo de uso satírico de la convención de la mirada panorámica, aunque no se satiriza propiamente esta convención, sino el uso que el escritor romántico pueda hacer de ella. En este caso, el sobrino de El curioso parlante en el artículo El Romanticismo y los románticos:

interpeló a su calenturienta musa, colocándose con ella en la región aérea don se forman las románticas tormentas; y mirando desde aquella altura esta sociedad terrena, reducida por la distancia a una pequeñez microscópica, aplicado al ojo izquierdo el catalejo romántico, que todo lo abulta, que todo lo descompone, inflamóse al fin su fosfórica fantasía, y compuso un drama.” (Mesonero Romanos 1993: 302-3).

\section{Bibliografía}

Assaf, Francis. 1984. "Aspects picaresques du Diablo Cojuelo”. Revista Canadiense de Estudios Hispánicos. 8 (3): 405-12.

Aumont, Jacques. 1997. El ojo interminable. Cine y pintura. Barcelona: Editorial Paidós.

Balzac, Honoré de. 2001. Papá Goriot. Madrid: Editorial Espasa Calpe.

Benjamin, Walter. 1998. "II. “El «flâneur». El París del Segundo Imperio en Baudelaire”. En: Iluminaciones II. Poesía y capitalismo. Madrid: Taurus, 49-83.

«Clarín», Leopoldo Alas. 2000. La Regenta (Prólogo de Emilio Peral). Madrid: Editorial Edaf.

Dickens, Charles. 1957. Sketches by Boz. Illustrative of every-day life and every-day people (With 55 illustrations by Geoge Cruiksank and 'Phiz' and an Introduction bay Thea Holme). London: Oxford University Press.

Engels, Federico. 1974. La situación de la clase obrera en Inglaterra. México D.F., México: Ediciones de Cultura Popular.

Epstein Nord, Deborah. 1995. Walking the Victorian streets. Women, representation, and the city. Ithaca, N.Y.: Cornell University Press.

Fergusson, Priscilla Parkhurst. 1989. "Reading revolutionary Paris". En: Philippe Desan; Priscilla Parkhurst Ferguson y Wendy Griswold (eds.). Literature and social practice. Chicago: University of Chicago Press, 46-68. 
Galdós, Benito Pérez. 1972. Los artículos de Galdós en La Nación. Madrid: Ínsula.

Gutiérrez, Juan María. 2000. "El hombre hormiga". En: Moreiro, Julián. Costumbristas de Hispanoamérica. Cuadros, leyendas y tradiciones. Madrid: Editorial Edaf, 57-61.

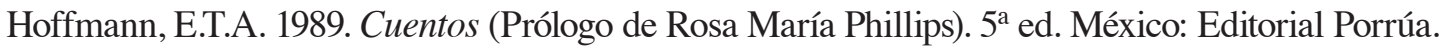

Hugo, Víctor. 1970. Los miserables. México D.F.: Editorial Porrúa.

2001. Nuestra señora de París. Madrid: Editorial Espasa Calpe.

Larra, Mariano José de. 1992. "El mundo todo es máscaras. Todo el año es Carnaval". En: Artículos (Ed. de Enrique Rubio). Madrid: Editorial Cátedra, 203-217.

Marechal, Leopoldo. 1997. Adán Buenosayres. San José: ALLCA.

Mesonero Romanos, Ramón de. 1967a. Escenas matritenses. Madrid: Cátedra.

1967b. “El dominó”. En: Escenas matritenses. Madrid: Cátedra, 229-238.

1967c. "El Observatorio de la Puerta del Sol". En: Escenas matritenses. Barcelona: Editorial Bruguera, 353-357.

1993a. Escenas y tipos matritenses. Madrid: Cátedra.

1993b. "Paseo por las calles". En: Escenas y tipos matritenses. Barcelona: Editorial Bruguera, 215-229.

1993c. "El camposanto". En: Escenas y tipos matritenses. Barcelona: Editorial Bruguera, 196-205.

Pérez Galdós, Benito. 1942. "Desde la veleta”. En: Obras Completas. Tomo 6, 1617-1618.

Stewart, Susan. 1984. On longing. Baltimore: John Hopkins University Press.

Vélez de Guevara, Luis. 1989. El diablo cojuelo. Madrid: Editorial Cátedra. 